\title{
LAS MEDIDAS DE SALVAGUARDIA EN LA COMUNIDAD ANDINA'
}

\author{
Hugo R. Gómez Apac*
}

\begin{abstract}
"Dissents speak to a future age. It's not simply to say, "My colleagues are wrong, and I would do it this way." But the greatest dissents do become court opinions and gradually over time, their views become the dominant view. So that's the dissenter's hope: that they are writing not for today, but for tomorrow."
\end{abstract}

US Supreme Court Justice Ruth Bader Ginsburg

\section{INTRODUCCIÓN}

El presente capítulo tiene por objeto explicar el desarrollo jurisprudencial llevado a cabo por el Tribunal de Justicia de la Comunidad Andina (en adelante, el Tribunal o el TJCA) con respecto a las medidas de salvaguardia comercial previstas en el capítulo XI del Acuerdo de Cartagena.

* Abogado por la Universidad Nacional Mayor de San Marcos y Magíster en Derecho de la Empresa por la Universidad Peruana de Ciencias Aplicadas. Actualmente, se desempeña como Magistrado Principal por la República del Perú en el Tribunal de Justicia de la Comunidad Andina, y profesor en la Maestría de Derecho de la Propiedad Intelectual y de la Competencia de la Pontificia Universidad Católica del Perú, en la Maestría de Derecho Administrativo Económico de la Universidad del Pacífico, en la Maestría de Derecho Constitucional de la Universidad San Gregorio de Portoviejo del Ecuador, y en la Escuela de Derecho de la Universidad Científica del Sur.

Ha sido Presidente del Consejo Directivo del Organismo de Evaluación y Fiscalización Ambiental (OEFA), y Director Nacional de Asuntos Jurídicos en el Ministerio de Justicia y Derechos Humanos. En el Instituto Nacional de Defensa de la Competencia y de la Protección de la Propiedad Intelectual (Indecopi) ha sido Secretario Técnico de la Comisión de Libre Competencia, Asesor de la Gerencia Legal, Secretario Técnico de la Sala de Defensa de la Competencia y Vicepresidente de la Comisión de Protección al Consumidor.

1 Una versión del presente trabajo académico aparece como capítulo III en el libro: AA.VV., Comercio Internacional \& Derecho Aduanero y Tributario en la Comunidad Andina, Pontificia Universidad Católica del Ecuador - Sede Ambato, Ambato, 2021, pp. 117-153. 
Para tal efecto, primero se expondrá el contexto general de la regulación de dichas medidas en el marco de la Organización Mundial del Comercio (en lo sucesivo, la OMC). Luego se abordará el tratamiento normativo de las referidas medidas en el ordenamiento jurídico comunitario andino. A continuación se desarrollarán los criterios jurídicos esbozados por el Tribunal con relación a las mencionadas salvaguardias en sentencias e interpretaciones prejudiciales emitidas entre 1987 y hasta antes del año 2018. Finalmente, el artículo analizará dos sentencias expedidas el año 2018, la primera (de abril) vinculada a una salvaguardia por desequilibrio en la balanza de pagos global, y la segunda (de agosto) relacionada con una salvaguardia por devaluación monetaria, en ambos casos por medidas de defensa comercial adoptadas por Ecuador. Resulta pertinente indicar que los criterios contenidos en la última sentencia son los vigentes a la fecha, por lo que los países miembros del proceso de integración subregional andino (Bolivia, Colombia, Ecuador y Perú) y la Secretaría General de la Comunidad Andina (en adelante, la SGCA) deben respetar dichos criterios al momento de adoptar, o autorizar, salvaguardias comerciales, según corresponda.

El énfasis puesto en las dos sentencias emitidas el 2018 se justifica por tres razones: (i) son los dos últimos pronunciamientos del Tribunal en materia de salvaguardia comercial; (ii) el autor del presente capítulo participó como magistrado en la discusión de tales providencias judiciales; y, (iii) porque, de alguna manera, evidencian cómo a nivel de las altas cortes de justicia, lo que en un primer momento, una determinada posición jurídica constituye un voto en minoría, luego puede convertirse en la posición mayoritaria (o de unanimidad) del colegiado, lo que a su vez explica la cita inicial de la jueza Ginsburg de la Corte Suprema de los Estados Unidos de América, fallecida el año pasado.

En la sentencia de abril de 2018, a diferencia del voto en mayoría, el de la minoría consideró como criterio jurídico interpretativo que un requisito de la salvaguardia por desequilibrio en la balanza de pagos global es la existencia de una relación de causa y efecto entre el incremento de las importaciones provenientes de uno o más países miembros y dicho desequilibrio. En la sentencia de agosto de 2018, el referido criterio jurídico fue adoptado por unanimidad, pues se afirmó, con relación a las cuatro modalidades de salvaguardia comercial previstas en el capítulo XI del Acuerdo de Cartagena, que debe existir una relación de causa y efecto entre el incremento de las importaciones y el daño (o amenaza de daño) de que se trate.

\section{LAS MEDIDAS DE SALVAGUARDIA}

Las salvaguardias son medidas de defensa comercial que tienen por objeto proteger a un sector de la industria nacional frente al incremento imprevisto de las importaciones de productos similares o directamente competidores - a los producidos por dicha industria- que causa o amenaza con causar un dańo grave al referido sector ${ }^{2,3}$. A diferencia de otras medi-

2 Delpiano Lira, Cristián. Medidas de salvaguardia y exclusiones regionales en la jurisprudencia de la Organización Mundial del Comercio. Revista Chilena de Derecho, vol. 42, núm. 2, Santiago, 2015, p. 545. Pontificia Universidad Católica de Chile. Disponible en: https:// scielo.conicyt.cl/scielo.php?script $=$ sci_arttext\&pi$\mathrm{d}=\mathrm{S} 0718-34372015000200007$

3 La OMC define a las salvaguardias como «... medidas "de urgencia” con respecto al aumento de las importaciones de determinados productos cuando esas importaciones hayan causado o amenacen causar un daño grave a la rama de producción nacional del Miembro importador...». Definición extraída de: https://www.wto.org/spanish/tratop_s/safeg_s/safeg_info_s.htm 
das de defensa comercial, como los derechos antidumping (frente al dumping) y compensatorios (frente a los subsidios), las salvaguardias no constituyen una respuesta (consecuencia jurídica) a un acto ilícito -el dumping y los subsidios califican como actos de competencia desleal en el comercio internacional-, sino que traducen la aplicación de una política comercial que tiene como propósito proteger a una rama de la industria nacional frente a la dura competencia que significa el incremento imprevisible ${ }^{4}$ de las importaciones de productos competidores. Las medidas de salvaguardia toman la forma de un incremento de los aranceles $^{5}$ (arancel específico o ad valorem), o de cuotas o cupos máximos de importación.

La figura de las medidas de salvaguardia aparece en el artículo XIX del Acuerdo General sobre Aranceles Aduaneros y Comercio (GATT) de 1947 como «medidas de urgencia sobre la importación de productos determinados», a efectos de dotar a los países miembros de dicho acuerdo de una válvula de escape frente a las obligaciones que imponía el integrarse al comercio internacional luego de la segunda guerra mundial. Las disposiciones del GATT de 1947 se incorporaron al Acuerdo General sobre Aranceles Aduaneros y Comercio (GATT)

4 Como bien afirma Gabriel Ibarra, la cláusula de escape (o de salvaguardia) se activa frente a la evolución «imprevista» de circunstancias que llevan a un incremento de las importaciones en tal cantidad o en condiciones tales que causen o amenacen causar un perjuicio grave a los productores de bienes similares directamente competidores. (Gabriel Ibarra Pardo, Las grandes controversias del multilateralismo. Crisis del principio de la Nación más favorecida, distorsiones de la competencia y temas ambientales, Facultad de Ciencias Jurídicas de la Pontificia Universidad Javeriana - Legis Editores S.A., Bogotá, 2018, p. 201).

5 «En términos generales, la cláusula de escape autoriza a un país para incrementar el arancel por encima del consolidado" (Gabriel Ibarra Pardo, Op. cit.), o por encima de los compromisos asumidos (Cristián Delpiano Lira, Op. cit.). de 1994, y este se incorporó al Anexo 1A del Acuerdo que crea la $\mathrm{OMC}^{6}$, el cual entró en vigor el 1 de enero de 1995. En el marco de la OMC, las medidas de salvaguardia se encuentran reguladas en el artículo XIX del GATT de 1994 y en el Acuerdo de Salvaguardias (que también forma parte del Anexo 1A del Acuerdo que crea la OMC).

De conformidad con lo dispuesto en el artículo XIX del GATT de 1994, si, como consecuencia de la evolución imprevista de las circunstancias y por efecto de las obligaciones, incluidas las concesiones arancelarias, contraídas por una parte contratante del Acuerdo que crea la OMC, las importaciones de un producto en el territorio de esta parte contratante han aumentado en tal cantidad y se realizan en condiciones tales que causan o amenazan causar un daño grave a los fabricantes nacionales de productos similares o directamente competidores en ese territorio, dicha parte contratante podrá, en la medida y durante el tiempo que sean necesarios para prevenir o reparar ese daño, suspender total o parcialmente la obligación contraída con respecto al referido producto o retirar o modificar la concesión.

El artículo 2 del Acuerdo sobre Salvaguardias, por su parte, establece que un país miembro de la OMC solo podrá aplicar una medida de salvaguardia a un producto si dicho país ha determinado, con arreglo a las disposiciones contenidas en el mencionado acuerdo, que las importaciones de ese producto en su territorio han aumentado en tal cantidad, en términos absolutos o en relación con la producción nacional, y se realizan en condiciones tales que causan o amenazan causar un daño grave a la rama de producción nacional que fabrica pro-

6 El Acuerdo de Marrakech por el que se establece la OMC y sus Anexos. 
ductos similares o directamente competidores. Las medidas de salvaguardia se aplicarán al producto importado independientemente de la fuente de donde proceda.

Las medidas de salvaguardia son válvulas de escape a los compromisos arancelarios asumidos al amparo de la OMC, en el contexto de los acuerdos de libre comercio, o en el marco de los procesos de integración económica y social como es el caso de la Comunidad Andina.

\section{LAS SALVAGUARDIAS EN LA COMUNIDAD ANDINA}

La Comunidad Andina es un proceso de integración económica y social que tiene por objeto el desarrollo equilibrado y equitativo de sus países miembros. Su tratado fundacional es el Acuerdo de Cartagena, firmado el 26 de mayo de 19697. El artículo 1 de este tratado internacional establece que la meta del proceso de integración subregional andino es la creación de un mercado común, lo que requiere como fases previas, primero la conformación de un área de libre comercio, y segundo un arancel externo común y una unión aduanera.

A la fecha, no obstante haber pasado 51 años, se ha alcanzado solo lo primero, un área de libre comercio, el cual se sustenta en el llamado «programa de liberación», contemplado en el capítulo VI del Acuerdo de Cartagena, por virtud del cual se han eliminado los gravámenes y las restricciones de todo orden que inciden sobre la importación de productos originarios de los países miembros. En aplicación del programa de liberación, los productos originarios de un país miembro ingresan a otro país miem-

\footnotetext{
7 A la fecha, codificado por la Decisión 563 de la Comisión de la Comunidad Andina, publicada en la Gaceta Oficial del Acuerdo de Cartagena 940 del 1 de julio de 2003.
}

bro sin pagar aranceles (derechos aduaneros) y cualquier otro recargo de efecto equivalente, sea de carácter fiscal, monetario o cambiario, que incida en las importaciones. En consecuencia, está prohibida cualquier medida de carácter tributario, administrativo, financiero o cambiario, mediante la cual un país miembro impida o dificulte las importaciones provenientes de otro país miembro. ${ }^{8}$

Dada la existencia de un área de libre comercio, las importaciones provenientes de un país miembro pueden aumentar inesperada y significativamente y dañar, o amenazar con dañar, a un sector de la industria local del país miembro importador, o a su economía, por lo que como medida de escape - de carácter excepcional- a las obligaciones que impone el programa de liberación, el Acuerdo de Cartagena prevé que el país importador puede dictar medidas de salvaguardia destinadas a restringir el ingreso de tales importaciones.

\subsection{El Acuerdo de Cartagena ${ }^{9}$}

El capítulo XI del Acuerdo de Cartagena trata de las cláusulas de salvaguardia, «...que son medidas de carácter correctivo que puede adoptar un país miembro cuando las importaciones provenientes de otro país miembro le causan o amenazan con causarle un determinado daño» ${ }^{10}$. Dicho capítulo regula 4 tipos de

8 Artículos 72 y 73 del Acuerdo de Cartagena.

9 En el presente trabajo no se abordarán las medidas previstas en los artículos 90 y 91 (del capítulo IX) del Acuerdo de Cartagena relacionados con las importaciones de productos agropecuarios.

10 Gómez, H. El ordenamiento jurídico comunitario andino. En: Gómez, H. (Director). Apuntes de Derecho Comunitario Andino. A propósito de los 50 años de la Comunidad Andina y los 40 años de creación de su Tribunal de Justicia, Portoviejo: Universidad San Gregorio de Portoviejo, Editorial San Gregorio S.A., 2019, p. 62. 
salvaguardia: (i) por desequilibrio en la balanza de pagos global (artículo 95); (ii) por el cumplimiento del programa de liberación (art.96); (iii) por productos específicos (art. 97); y, (iv) por devaluación monetaria (art. 98).

La salvaguardia por desequilibrio en la balanza de pagos global tiene por objeto corregir el desequilibrio en la balanza de pagos de un país miembro ocasionado por las importaciones de otro u otros países miembros. El artículo 95 dispone que un país miembro que haya adoptado medidas para corregir el mencionado desequilibrio, podrá extender dichas medidas, previa autorización de la SGCA, con carácter transitorio y en forma no discriminatoria, al comercio intrasubregional de productos incorporados al programa de liberación ${ }^{11,12}$. Cuando la situación de desequilibrio exigiere providencias inmediatas, el país miembro interesado podrá, con carácter de emergencia, aplicar las medidas previstas, debiendo comunicarlas de inmediato a la SGCA, la que se pronunciará dentro de los 30 días siguientes, autorizándolas, modificándolas o suspendiéndolas. Si la aplicación de la salvaguardia se prolongase por más de un año, la SGCA propondrá a la Comisión de la Comunidad Andina (en adelante, la Comisión), por iniciativa propia o a pedido

Disponible en: https://www.tribunalandino.org.ec/libros/ LIBRO_DERECHO.pdf

11 El programa de liberación tiene por objeto «...eliminar los aranceles y cualquier otro tipo de gravamen o recargo, sean de carácter tributario, monetario o cambiario, que incidan sobre los productos que un país miembro importe de otro país miembro, así como eliminar todo tipo de restricción al comercio, es decir, cualquier medida administrativa, financiera o cambiaria mediante la cual un país miembro impida o dificulte las importaciones provenientes de otro país miembro...» (Gómez, H. op. cit., pp. 57 y 58).

12 El referido artículo agrega que los países miembros procurarán que la imposición de restricciones en virtud de la situación del balance de pagos no afecte, dentro de la subregión, al comercio de los productos incorporados al programa de liberación. de cualquier país miembro, el inicio inmediato de negociaciones a fin de procurar la eliminación de las restricciones adoptadas ${ }^{13}$.

La salvaguardia por el cumplimiento del programa de liberación tiene por finalidad corregir los perjuicios graves (o amenaza de estos) a la economía de un país miembro (o a un sector significativo de su actividad económica) que sean consecuencia del cumplimiento del programa de liberación; es decir, como consecuencia "... de las importaciones sin gravámenes (o sin restricciones de cualquier naturaleza) provenientes de otro u otros paises miembros... ${ }^{14} \mathrm{El}$ artículo 96 establece que si el cumplimiento del programa de liberación causa o amenaza causar perjuicios graves a la economía de un país miembro o a un sector significativo de su actividad económica, dicho país podrá, previa autorización de la SGCA, aplicar medidas correctivas de carácter transitorio y en forma no discriminatoria. Agrega que, cuando fuere necesario, la SGCA deberá proponer a la Comisión medidas de cooperación colectiva destinadas a superar los inconvenientes surgidos ${ }^{15}$.

13 El capítulo VII (Salvaguardia por Balanza de Pagos) de la Decisión 439 (Marco General de Principios y Normas para la Liberalización del Comercio de Servicios en la Comunidad Andina), publicado en la Gaceta Oficial del Acuerdo de Cartagena 347 del 17 de junio de 1998, establece que un país miembro que haya adoptado medidas restrictivas del comercio de servicios con terceros países, para hacer frente a la existencia o amenaza de graves dificultades financieras exteriores o de balanza de pagos, podrá extender dichas medidas, previa autorización de la SGCA, al comercio intrasubregional de servicios. Esta salvaguardia por balanza de pagos se encuentra regulada en los artículos 20 y 21 de la Decisión 439.n 439.

14 Gómez, H. Op. cit., p. 62.

15 Adicionalmente, el artículo 96 del Acuerdo de Cartagena precisa que la SGCA deberá analizar periódicamente la evolución de la situación con el objeto de evitar que las medidas restrictivas se prolonguen más allá de lo estrictamente necesario o considerar nuevas fórmulas de cooperación si fuere procedente. 
Cuando los perjuicios sean tan graves que exijan providencias inmediatas, el país miembro afectado podrá aplicar medidas correctivas provisionalmente y con carácter de emergencia, sujetas al posterior pronunciamiento de la SGCA. Dichas medidas deberán causar el menor perjuicio posible al programa de liberación $y$, mientras se apliquen en forma unilateral, no podrán significar una disminución de las importaciones del producto o productos de que se trate, con respecto al promedio de los 12 meses anteriores. El país miembro que adopte las medidas deberá comunicarlas inmediatamente a la SGCA y esta se pronunciará sobre ellas dentro de los 30 días siguientes, ya sea para autorizarlas, modificarlas o suspenderlas.

La salvaguardia por productos específicos tiene el propósito de corregir las perturbaciones en la producción nacional de productos específicos de un país miembro debido a las importaciones de productos originarios de la subregión. Sobre el particular, el artículo 97 establece que cuando ocurran importaciones de productos originarios de la subregión andina, en cantidades o en condiciones tales que causen perturbaciones en la producción nacional de productos específicos de un país miembro, este podrá aplicar medidas correctivas, no discriminatorias, de carácter provisional, sujetas al posterior pronunciamiento de la SGCA. El país miembro que aplique las medidas correctivas, en un plazo no mayor de 60 días, deberá comunicarlas a la SGCA y presentar un informe sobre los motivos que fundamentan su aplicación. La SGCA, dentro de un plazo de 60 días siguientes a la fecha de recepción del mencionado informe, verificará la perturbación y el origen de las importaciones causantes de la misma y emitirá su pronunciamiento, ya sea para suspender, modificar o autorizar dichas medidas, las que solamente podrán aplicarse a los productos del país miembro donde se hubiere originado la perturbación. Las medidas correctivas que se apliquen deberán garantizar el acceso de un volumen de comercio no inferior al promedio de los tres últimos años.

La salvaguardia por devaluación monetaria tiene como objetivo corregir la alteración a las condiciones normales de competencia causada por la devaluación efectuada por uno o más países miembros. Con relación a esto, el artículo 98 dispone que si una devaluación monetaria efectuada por uno de los países miembros altera las condiciones normales de competencia, el país que se considere perjudicado podrá plantear el caso a la SGCA, la que deberá pronunciarse breve y sumariamente. Verificada la perturbación por la SGCA, el país perjudicado podrá adoptar medidas correctivas de carácter transitorio y mientras subsista la alteración, dentro de las recomendaciones de la SGCA. En todo caso, dichas medidas no podrán significar una disminución de los niveles de importación existentes antes de la devaluación. Sin perjuicio de la aplicación de las medidas transitorias aludidas, cualquiera de los países miembros podrá pedir a la Comisión una decisión definitiva del asunto. El país miembro que devaluó podrá pedir a la SGCA, en cualquier momento, que revise la situación a fin de atenuar o suprimir las mencionadas medidas correctivas. El dictamen de la SGCA podrá ser enmendado por la Comisión.

El artículo 98 del Acuerdo de Cartagena agrega que, el país que se considere perjudicado, al presentar el caso a la SGCA, podrá proponer las medidas de protección adecuadas a la magnitud de la alteración planteada, acompañando los elementos técnicos que fundamenten su planteamiento. La SGCA podrá solicitar la información complementaria que estime con- 
veniente. El pronunciamiento breve y sumario de la SGCA deberá producirse dentro del plazo de 1 mes, contado a partir de la fecha de recepción de la solicitud. Si la SGCA no se pronunciare en dicho plazo y el país solicitante considera que la demora en el pronunciamiento puede acarrearle perjuicios, podrá adoptar las medidas iniciales por él propuestas, comunicando de inmediato este hecho a la SGCA, la cual, en su pronunciamiento posterior, deberá decidir sobre el mantenimiento, modificación o suspensión de las medidas aplicadas. En su pronunciamiento, la SGCA tendrá en cuenta, entre otros elementos de juicio, los indicadores económicos relativos a las condiciones de competencia comercial en la subregión andina que la Comisión haya adoptado con carácter general (a propuesta de la SGCA), las características propias de los sistemas cambiarios de los países miembros y los estudios que al respecto realice el Consejo Monetario y Cambiario.

Adicionalmente, el artículo 98 precisa que mientras no se haya adoptado el sistema de indicadores económicos por la Comisión, la SGCA procederá con sus propios elementos de juicio. No obstante, si durante el lapso que media entre la presentación referida y el pronunciamiento de la SGCA, a juicio del país miembro solicitante existen antecedentes que hagan temer fundadamente que, como consecuencia de la devaluación, se producirán perjuicios inmediatos que revistan gravedad para su economía, que requieran con carácter de emergencia la adopción de medidas de protección, podrá plantear la situación a la SGCA, la cual, si considera fundada la petición, podrá autorizar la aplicación de medidas adecuadas, para lo cual dispondrá de un plazo de siete días continuos. El pronunciamiento definitivo de la SGCA sobre la alteración de las condiciones normales de competencia determinará, en todo caso, el mantenimiento, modificación o suspensión de las medidas de emergencia autorizadas. Las medidas que se adopten de conformidad con este artículo no podrán significar una disminución de las corrientes de comercio existentes antes de la devaluación.

\subsection{La Decisión 389 de la Comisión del Acuerdo de Cartagena}

La Decisión 389 ${ }^{16}$, Reglamento para la aplicación de la cláusula de salvaguardia prevista en el artículo 78 (hoy artículo 95) del Acuerdo de Cartagena, regula el procedimiento a seguir para solicitar a la Junta (la SGCA) autorización para aplicar una salvaguardia por desequilibrio en la balanza de pagos global, así como las medidas correctivas en las que se pueden expresar dicha salvaguardia: recargos a las importaciones; prescripciones en materia de depósito previo a la importación u otras medidas que repercutan en el precio de las mercaderías; y, de manera excepcional, restricciones cuantitativas cuando, debido a una situación crítica en la balanza de pagos, las medidas basadas en los precios no puedan impedir su brusco empeoramiento.

\section{CRITERIOS JURISPRUDENCIALES EN MATERIA DE SALVAGUARDIAS: 1987- 2017}

En la presente sección se resumen los criterios jurídicos esbozados por el TJCA con relación a las salvaguardias previstas en el capítulo XI del Acuerdo de Cartagena, contenidos en la jurisprudencia emitida desde 1987 y hasta antes del 2018. ${ }^{17}$

16 De la Comisión del Acuerdo de Cartagena, de fecha 2 de julio de 1996, publicada en la Gaceta Oficial del Acuerdo de Cartagena 211 del 17 de julio de 1996.

17 Esta sección ha sido extraída de los siguientes documentos: (i)Anexo I del Voto disidente a la Sentencia del 26 de abril de 2018 emitida en el Proceso 04-AN-2015, sentencia 


\subsection{Salvaguardia por desequilibrio en la ba- lanza de pagos global}

Con relación a la salvaguardia por desequilibrio en la balanza de pagos, el Tribunal estableció en su jurisprudencia ${ }^{18}$, los siguientes criterios jurídicos:

- Es una medida sujeta a parámetros muy estrictos, y de naturaleza excepcional, correctiva, no discriminatoria y transitoria;

- $\mathrm{Su}$ aplicación requiere la autorización previa de la SGCA, excepto en casos de emergencia, situación en la cual el órgano ejecutivo del proceso de integración se pronunciará con posterioridad;

- Está concebida para corregir situaciones transitorias de desequilibrio de la balanza de pagos;

- Debe existir una relación de causa y efecto; es decir, se debe demostrar la incidencia que tienen las importaciones de origen subregional en el desequilibrio de la balanza de pagos global del país solicitante;

publicada en la Gaceta Oficial del Acuerdo de Cartagena 3293 del 29 de mayo de 2018.

(ii)Anexo I del Informe 03-MP-TJCA-2018 del 31 de mayo de 2018 emitido en el Proceso 01-AN-2015.

(iii)Anexo II del Informe 04-MP-TJCA-2018 del 1 de junio de 2018 emitido en el Proceso 01-AN-2015.

Se puede tener acceso a los mencionados documentos siguiendo las pautas establecidas en el artículo 2 del Reglamento Interno del Tribunal de Justicia de la Comunidad Andina, aprobado mediante el Acuerdo 01/2020 del 29 de junio de 2020, publicado en la Gaceta Oficial del Acuerdo de Cartagena 4011 del 30 de junio de 2020.

18 Interpretación Prejudicial 05-IP-90 de fecha 22 de julio de 1994, publicada en la Gaceta Oficial del Acuerdo de Cartagena 162 del 9 de setiembre de 1994; Sentencia del 17 de agosto de 1998 recaída en el Proceso 04-AN-97, publicada en la Gaceta Oficial del Acuerdo de Cartagena 373 del 21 de setiembre de 1998; Sentencia del 21 de julio de 1999 recaída en el Proceso 07-AI-98, publicada en la Gaceta Oficial del Acuerdo de Cartagena 490 del 4 de octubre de 1999; e, Interpretación Prejudicial 103-IP-2000 del 2 de mayo de 2001, publicada en la Gaceta Oficial del Acuerdo de Cartagena 677 del 13 de junio de 2001.
- La salvaguardia se aplica al país que ha originado la perturbación; $y$,

- Los países miembros procurarán que la salvaguardia no afecte el comercio de los productos incorporados al programa de liberación.

\subsection{Salvaguardia por cumplimiento del pro- grama de liberación}

Tratándose de la salvaguardia por cumplimiento del programa de liberación, el Tribunal ${ }^{19}$ señaló los siguientes criterios jurídicos:

- Es una medida sujeta a parámetros muy estrictos, y de naturaleza correctiva, no discriminatoria y transitoria;

- Por su naturaleza excepcional, debe ser aplicada de manera restringida y no extensiva. Se trata de una medida excepcional y restrictiva aplicable a la importación de "productos" originarios del territorio de cualquier país miembro;

- Debe existir una relación de causa y efecto entre el incremento de las importaciones (fruto del programa de liberación) y los perjuicios graves (o amenaza de perjuicios graves) a la economía del país miembro o a un sector significativo de su actividad económica;

- Su aplicación requiere la autorización previa de la SGCA, excepto en casos de emergencia, supuesto en el cual el país miembro puede aplicar medidas correctivas provisio-

19 Interpretación Prejudicial 05-IP-90 del 22 de julio de 1994, publicada en la Gaceta Oficial del Acuerdo de Cartagena 162 del 9 de setiembre de 1994; Sentencia del 17 de agosto de 1998 recaída en el Proceso 04-AN-97, publicada en la Gaceta Oficial del Acuerdo de Cartagena 373 del 21 de setiembre de 1998; Sentencia del 5 de julio de 2000 recaída en el Proceso 46-AI-99, publicada en la Gaceta Oficial del Acuerdo de Cartagena 592 del 17 de agosto de 2000; e, Interpretación Prejudicial 103-IP-2000 del 2 de mayo de 2001, publicada en la Gaceta Oficial del Acuerdo de Cartagena 677 del 13 de junio de 2001. 
nales unilaterales que están sujetas a pronunciamiento posterior del órgano ejecutivo del proceso de integración;

- Está sujeta al monitoreo de la SGCA, para evitar su prolongación en el tiempo;

- Mientras se aplique en forma unilateral, no podrá significar una disminución de las importaciones del producto o productos de que se trate, con respecto al promedio de los 12 meses anteriores;

- La medida adoptada debe causar el menor perjuicio posible al programa de liberación; $y$,

- Debe existir una relación directa entre la medida restrictiva (la salvaguardia) y su efecto sobre la disminución de las importaciones o en la posibilidad inminente de reducirlas.

\subsection{Salvaguardia por productos específicos (perturbación)}

En el caso de la salvaguardia por productos específicos, la jurisprudencia del TJCA ${ }^{20}$ determinó los siguientes criterios jurídicos:

20 Sentencia del 17 de agosto de 1998 recaída en el Proceso 04-AN-97, publicada en la Gaceta Oficial del Acuerdo de Cartagena 373 del 21 de setiembre de 1998; Interpretación Prejudicial 103-IP-2000 del 2 de mayo de 2001, publicada en la Gaceta Oficial del Acuerdo de Cartagena 677 del 13 de junio de 2001; Sentencia del 19 de agosto de 2003 recaída en el Proceso 23-AN-2002, publicada en la Gaceta Oficial del Acuerdo de Cartagena 991 del 2 de octubre de 2003; Sentencia del 7 de mayo de 2004 recaída en el Proceso 71-AN-2001, publicada en la Gaceta Oficial del Acuerdo de Cartagena 1086 del 25 de junio de 2004; Sentencia del 14 de abril de 2005 recaída en el Proceso 118-AI-2003, publicada en la Gaceta Oficial del Acuerdo de Cartagena 1206 del 13 de junio de 2005; Sentencia del 19 de abril de 2006 recaída en el Proceso 117-AN-2004, publicada en la Gaceta Oficial del Acuerdo de Cartagena 1347 del 25 de mayo de 2006; Sentencia del 17 de noviembre de 2006 recaída en el Proceso 214-AN-2005, publicada en la Gaceta Oficial del Acuerdo de Cartagena 1498 del 16 de mayo de 2007; e, Interpretación Prejudicial 111-IP-2011 del 15 de febrero de 2012, publicada en la Gaceta Oficial del Acuerdo de Cartagena 2046 del 27 de abril de 2012.
- Medida correctiva y de carácter provisional;

- No discriminatoria en su primera etapa, antes de ser revisada por la SGCA; sin embargo, una vez autorizada se aplica solo al país que ha originado la perturbación;

- Medida sujeta a un posterior procedimiento a cargo de la SGCA;

- Debe ser justificada, excepcional y autorizada;

- Debe existir una relación de causa (las importaciones) y efecto (la perturbación); es decir, la perturbación tiene que ser la consecuencia y resultado directo, inmediato y exclusivo, de las importaciones de un determinado producto que afectan al país miembro que decide aplicar la medida. La relación de causalidad es un elemento de especial consideración para la adopción de la medida por la SGCA y su posterior confirmación por el Tribunal;

- La SGCA debe verificar la perturbación en la producción nacional y el origen de las importaciones causantes de la misma, y emitirá su pronunciamiento a efectos de suspender, modificar o autorizar la medida. Debe verificarse la causa de la perturbación en la producción nacional y el origen de las importaciones, a efectos de suspender, modificar o autorizar las medidas por parte de la SGCA.

- Aplicable a los productos del país miembro en el que se originó la perturbación, después de que la medida ha sido aprobada por parte de la SGCA;

- Se debe garantizar el acceso a un volumen de comercio no inferior al promedio de los tres últimos ańos; $y$,

- Se debe procurar no afectar el comercio de productos incorporados dentro del programa de liberación. 


\subsection{Salvaguardia por devaluación monetaria}

Respecto de la salvaguardia por devaluación monetaria, la jurisprudencia del Tribunal $^{21}$ mencionó los siguientes criterios:

- La medida está sujeta a una interpretación restrictiva, como norma de excepción;

- Inicialmente la SGCA señala un término para la cesación de la medida de carácter no vinculante, es decir, bajo la fórmula de recomendación;

- Es una medida correctiva, transitoria y condicionada, puesto que se aplica «mientras subsista la alteración»;

- Su aplicación no puede significar disminución de los niveles de importación existentes antes de la devaluación;

- Corresponde al país miembro que adoptó la medida correctiva suspender sus efectos cuando hayan cesado los motivos que la originaron. Si el país miembro no lo hace, lo puede ordenar la SGCA o la Comisión, que tienen atribuciones para decidir en definitiva sobre el asunto;

- El país que devaluó puede pedir en cualquier momento a la SGCA que se pronuncie, adopte una resolución y suspenda la medida a pedido de parte, o niegue la suspensión, caso en el cual dicho país tiene derecho a recurrir ante la Comisión;

21 Sentencia del 10 de junio de 1987 recaída en el Proceso 1-N-86, publicada en la Gaceta Oficial del Acuerdo de Cartagena 21 del 15 de junio de 1987; Sentencia del 10 de junio de 1987 recaída en el Proceso 2-N-86, publicada en la Gaceta Oficial del Acuerdo de Cartagena 21 del 15 de junio de 1987; Sentencia del 17 de agosto de 1998 recaída en el Proceso 4-AN-97, publicada en la Gaceta Oficial del Acuerdo de Cartagena 373 del 21 de setiembre de 1998; e, Interpretación Prejudicial 103-IP-2000 del 2 de mayo del 2001, publicada en la Gaceta Oficial del Acuerdo de Cartagena 677 del 13 de junio de 2001.
- Debe existir una relación de causa y efecto; es decir, la devaluación ocurrida en otro u otros países miembros debe ser la causa de la perturbación en el país afectado (país solicitante de la medida correctiva);

- Se trata de una medida de duración indefinida pero condicionada, sujeta al permanente control de la SGCA; y,

- La SGCA tiene la facultad de mantener, modificar o suspender la medida de salvaguardia.

\section{CRITERIOS JURISPRUDENCIALES EN MATERIA DE SALVAGUARDIAS ESTA- BLECIDOS EL 2018}

\section{El Proceso 04-AN-2015: salvaguardia por desequilibrio en la balanza de pagos global (sentencia del 26 de abril de 2018)}

En los primeros meses del 2015, el saldo de la cuenta corriente de la balanza de pagos $^{22}$

22 «La balanza de pagos es un indicador macroeconómico que proporciona información sobre la situación económica del país de una manera general. Es decir, permite conocer todos los ingresos que recibe un país procedentes del resto del mundo y los pagos que realiza tal país al resto del mundo debido a las importaciones y exportaciones de bienes, servicios, capital o transferencias en un período de tiempo.

(...)

Cada una de estas balanzas [cuenta corriente, cuenta de capital, cuenta financiera y cuenta de errores y omisiones] dan un saldo independiente que puede ser positivo o negativo:

- Superávit: En el caso de que el saldo de un tipo de balanza sea positivo estaremos hablando de que la balanza está en superávit.

- Déficit: En el caso de que sea el saldo sea negativo. Sin embargo, no se busca el equilibro de cada una de estas balanzas por sí solas, sino el equilibrio global de la balanza de pagos. Por consiguiente, la balanza de pagos siempre estará en equilibro, por ejemplo un déficit en la balanza por cuenta corriente será compensado con un superávit en la balanza por cuenta de capital. Ya que si un país tiene más compras que ventas, el dinero lo debe obtener por algún lado, bien por 
global del Ecuador era deficitaria ${ }^{23}$, lo que significa que salían más dólares del país de los que entraban. Este fenómeno acaeció debido, principalmente, a la caída del precio internacional del petróleo, que de US\$91 en enero de 2014 bajó a US\$ 53 en diciembre del mismo año ${ }^{24}$. Tratándose de un país cuyos ingresos del exterior provienen en gran medida de sus exportaciones de petróleo, la caída del precio de este hidrocarburo implicó una importante

medio de inversiones o préstamos extranjeros.»

Economipedia, Balanza de Pagos, sitio web de Economipedia, 24 de enero de 2016.

Disponible en: https://economipedia.com/definiciones/ balanza-de-pagos.html (Consulta realizada el 10 de octubre de 2020)

23 "El saldo de la cuenta corriente de la balanza de pagos en el primer trimestre del 2015 registró el mayor déficit comparado con iguales períodos desde que Ecuador se dolarizó. En esta cuenta corriente se registran los dólares que entran y salen por exportaciones e importaciones de bienes y servicios, por renta, y por otras transferencias.

(...)

Este deterioro de la cuenta corriente durante los tres primeros meses del 2015 se explica por dos factores: la caída del precio del petróleo y la caída de las remesas de los migrantes, que vienen reduciéndose desde hace algunos años.»

Mónica Orozco, Déficit del primer trimestre en cuenta corriente, el peor desde la dolarización, El Comercio, 2015.

Disponible en: https://www.elcomercio.com/actualidad/ deficit-primer-trimestre-cuenta-corriente.html (Consulta efectuada el 10 de octubre de 2020)

24 «La baja del precio del petróleo, dada, según analistas, por una sobreoferta de los principales socios de la OPEP (Organización de Países Exportadores de Petróleo), que se niegan a disminuir su producción, empezó a sentirse en agosto pasado. Pero de manera más estrepitosa las últimas semanas del año. Hasta el miércoles 31 de diciembre el crudo WTI (West Texas Intermediate), que sirve de referencia para el que vende el país, se ubicó en \$ 53,27, cuando a inicios de ańo superaba los \$91. El ecuatoriano (Oriente y Napo) llegó el 22 de diciembre (último corte) a \$ 48, según el Sistema Nacional de Información; en el primer semestre estaba arriba de $\$ 92 . »$

El petróleo cae y complica la economía de Ecuador este 2015. El Universo, 2015. Disponible en: https://www. eluniverso.com/noticias/2015/01/04/nota/4396261/petroleo-cae-complica-economia-este-2015 (consultado el 3 de octubre de 2020) reducción en el ingreso de dólares del exterior.

Con el fin de corregir el desequilibrio en su balanza de pagos, mediante Resolución 0112015 del Comité de Comercio Exterior (COMEX) del 6 de marzo de $2015^{25}$, el gobierno ecuatoriano decidió establecer una sobretasa arancelaria temporal y no discriminatoria ad valorem de 45\%, 25\%, 15\% y 5\% sobre distintas subpartidas arancelarias, desde alimentos y bebidas hasta artículos de limpieza y electrodomésticos. Asimismo, excluyó de la aplicación de la salvaguardia a las importaciones provenientes de países de menor desarrollo relativo miembros de la Asociación Latinoamericana de Integración (ALADI), Bolivia y Paraguay ${ }^{26}$, conforme a la Resolución 70 del Comité de Representantes de la ALADI.

La medida fue comunicada a la SGCA. Los gobiernos de Colombia y Perú, así como gremios empresariales peruanos 27 , se opusieron a la salvaguardia ecuatoriana.

Por Resolución 1777 del 8 de abril de 2015², la SGCA admitió a trámite la solicitud de autorización de Ecuador y dispuso la apertura de

25 Publicada en el Suplemento del Registro Oficial del Ecuador 456 del 11 de marzo de 2015.

26 Resolución 6 del Consejo de Ministros de Relaciones Exteriores de las Partes Contratantes de la ALADI del 12 de agosto de 1980.-

«SEGUNDO. A los efectos de la aplicación de los tratamientos diferenciales previstos en el Tratado de Montevideo 1980, suscrito el 12 de agosto de 1980, se considerarán:

a) Países de menor desarrollo económico relativo: Bolivia, Ecuador y Paraguavi

b) Países de desarrollo intermedio: Colombia, Chile, Perú, Uruguay y Venezuela; y

c) Otros países miembros: Argentina, Brasil y México.»

27 La Cámara de Comercio de Lima, la Sociedad Nacional de Comercio Exterior del Perú, la Sociedad Nacional de Industrias de Perú y la Asociación de Exportadores del Perú - ADEX.

28 Publicada en la Gaceta Oficial del Acuerdo de Cartagena 2469 en la misma fecha. 
la investigación correspondiente, de conformidad con lo dispuesto en el artículo 95 del Acuerdo de Cartagena y la Decisión 389.

Mediante Resolución 1784 del 2 de junio de $2015^{29}$, la SGCA autorizó la medida de salvaguardia por desequilibrio de la balanza de pagos global de Ecuador, por un plazo máximo de un ańo contado desde el 11 de marzo de 2015. Asimismo, exceptuó a Bolivia de la aplicación de la referida medida, debido a su condición de país de menor desarrollo relativo dentro de la Comunidad Andina y tomando en cuenta su enclaustramiento geográfico.

El 9 de setiembre de 2015, Perú presentó demanda ante el TJCA solicitando la nulidad del pronunciamiento de la SGCA que había autorizado la salvaguardia ecuatoriana. En su demanda y alegatos finales, Perú argumentó que la Resolución 1784 de la SGCA era nula por falta de motivación, pues pese a que tanto Perú como Colombia alegaron que el desequilibrio de la balanza de pagos del Ecuador obedecía a problemas estructurales, la SGCA no incluyó en su análisis dicho aspecto. Asimismo, alegó que la SGCA no había verificado la situación de la balanza de pagos ecuatoriana conforme a la normativa andina, pues de esta no se desprendía que la SGCA únicamente debía evaluar los siguientes factores: (i) una disminución importante de las reservas internacionales; (ii) una amenaza inminente de disminución de reservas internacionales; $y$, (iii) que las reservas internacionales eran muy exiguas y se requería aumentarlas de acuerdo a una proporción razonable. Adicionalmente, arguyó que la salvaguardia autorizada por la SGCA era discriminatoria al excluir de su aplicación a Bolivia $y$, en consecuencia, violatoria de lo dispuesto

29 Publicada en la Gaceta Oficial del Acuerdo de Cartagena 2509 el mismo día. en el artículo 95 del Acuerdo de Cartagena. Finalmente, Perú señaló que la SGCA había omitido pronunciarse sobre la exclusión de Paraguay, exclusión contraria al principio de nación más favorecida contemplado en el artículo 139 del Acuerdo de Cartagena ${ }^{30}$.

La SGCA contestó la demanda solicitando que sea declarada infundada en todos sus extremos $^{31}$. En su escrito de contestación y alegatos finales, la SGCA argumentó que a pesar de que la normativa comunitaria aplicable a la solicitud del Ecuador no exigía que se analicen los factores estructurales, que en este caso habían afectado la economía ecuatoriana, dichos factores sí habían sido considerados en su análisis. Asimismo, respecto de que no se había verificado la situación de la balanza de pagos ecuatoriana conforme a la normativa andina, la SGCA alegó que la normativa andina no especificaba una metodología para el análisis del desequilibrio de una balanza de pagos, y que diversos pronunciamientos ${ }^{32}$ seńalaban que el análisis de las reservas internacionales, entre otros factores, eran requeridos para conocer el aludido desequilibrio, razón por la cual en la Resolución 1784 se decidió tomar en consideración si las reservas internacionales registra-

30 «Artículo 139.- Cualquier ventaja, favor, franquicia, inmunidad o privilegio que se aplique por un País Miembro en relación con un producto originario de o destinado a cualquier otro país, será inmediata e incondicionalmente extendido al producto similar originario de o destinado al territorio de los demás Países Miembros.

Quedan exceptuados del tratamiento a que se refiere el inciso precedente, las ventajas, favores, franquicias, inmunidades $y$ privilegios ya concedidos o que se concedieran en virtud de convenios entre Países Miembros o entre Países Miembros y terceros paises, a fin de facilitar el tráfico fronterizo."

31 Ecuador se apersonó al proceso en calidad de coadyuvante de la SGCA.

32 Del TJCA, del Órgano de Solución de Diferencias de la OMC, publicaciones especializadas y opiniones de expertos de la academia. 
ron reducciones importantes, o si existía una amenaza de disminución importante, o si sus niveles eran exiguos y se requería aumentarlos. Finalmente, sobre la exclusión de Paraguay, la SGCA mencionó que no entendía cómo la demandante relacionaba el hecho de que la salvaguardia autorizada a favor del Ecuador, sin discriminación respecto de las importaciones provenientes de Paraguay, implicaba una violación del principio de nación más favorecida.

El 26 de abril de 2018, el Tribunal emitió Sentencia $^{33}$ sin llegar a una posición unánime. El voto en mayoría declaró infundada en todos sus extremos la demanda. Respecto del desequilibrio en la balanza de pagos global del Ecuador, dicho voto sostuvo que, si bien la SGCA no había realizado un análisis de los factores estructurales de la economía ecuatoriana que generaron el desequilibrio de su balanza de pagos, esta omisión resultaba intrascendente respecto de la validez de la Resolución 1784. Lo relevante era que la SGCA sí había analizado los factores coyunturales que habían incidido en el desequilibrio de la balanza de pagos global.

Tratándose de la verificación de la situación de la balanza de pagos ecuatoriana conforme a la normativa andina, para los magistrados que conformaban la posición en mayoría la decisión de la SGCA de acudir a otras fuentes del derecho, ante la falta de regulación de una metodología sobre la materia en cuestión, fue pertinente. Sobre este punto, coincidió con la SGCA respecto de que el análisis del desequilibrio de una balanza de pagos debía tomar en cuenta la razón por la cual el país miembro solicitaba la autorización de la medida. En este caso, Ecuador había adoptado la medida con el propósito

33 Recaída en el Proceso 04-AN-2015, publicada en la Gaceta Oficial del Acuerdo de Cartagena 3293 del 29 de mayo de 2018. de regular el nivel general de las importaciones, garantizar la liquidez de su economía y evitar la disminución de las reservas internacionales generada, principalmente, por la baja en los precios internacionales del petróleo.

Respecto de la exclusión de Bolivia, para la posición en mayoría del TJCA, de una interpretación teleológica y sistemática de los artículos 3 (literal j) y 109 del Acuerdo de Cartagena se desprendía que el trato preferencial reconocido a Bolivia (y a Ecuador) se aplicaba también a las salvaguardias comerciales, por lo que la exclusión de Bolivia de la salvaguardia ecuatoriana no resultaba discriminatoria. Finalmente, tratándose de la exclusión de Paraguay, para el voto en mayoría, la SGCA había autorizado la salvaguardia por desequilibrio en la balanza de pagos sin discriminación alguna debido a que, en el marco de sus atribuciones previstas en el artículo 95 del Acuerdo de Cartagena, había modificado la Resolución 011-2015 del COMEX, excluyendo a Paraguay de su aplicación.

El voto en minoría ${ }^{34}$ sostuvo que la mayoría no tomó en consideración los criterios jurisprudenciales expuestos en el párrafo $4.1 \mathrm{del}$ presente capítulo, como tampoco analizó si la Resolución 1784 había violado o no el objeto, contenido y alcance del artículo 95 del Acuerdo de Cartagena ${ }^{35}$. El referido voto advirtió que este tipo de salvaguardia tenía por objeto corregir el desequilibrio en la balanza de pagos global de un país miembro ocasionado por las importaciones de otro u otros países miembros; es decir, que su aplicación estaba condicionada

34 Sostenido por 2 magistrados del TJCA, entre ellos, el autor del presente capítulo.

35 El voto en minoría precisó que el parámetro de control no solo es el texto de la norma andina sino también la interpretación auténtica de dicha norma realizada por el TJCA a través de sus interpretaciones prejudiciales, en las que define el objeto, contenido y alcance de la normativa andina. 
a que el desequilibrio que se pretendía corregir hubiese sido producido por las importaciones provenientes de uno o más de los países miembros de la Comunidad Andina. Asimismo, hizo un recuento de las características comunes a esta salvaguardia ${ }^{36}$, y en tal sentido señaló que se trataba de una medida de naturaleza correctiva, no discriminatoria y transitoria; que debía existir una relación de causa y efecto entre las importaciones de origen subregional y el desequilibrio existente; que debía aplicarse al país que había originado la perturbación; y que la restricción impuesta debía procurar no afectar el comercio de los productos incorporados al programa de liberación.

Para el voto en minoría, en materia de salvaguardia por desequilibrio en la balanza de pagos global, ni la normativa andina ni la jurisprudencia previa del TJCA contemplaban un tratamiento especial en beneficio de Ecuador o Bolivia (países con menor grado de desarrollo), como sí lo hacían expresamente respecto de otro tipo de medidas ${ }^{37}$, por lo que en su opinión la medida sí era discriminatoria. Respecto de la exclusión de Paraguay, la posición en minoría precisó que la mayoría confundió lo cuestionado por la demandante, pues esta no había sostenido que la Resolución 1784 era nula porque se había excluido a Paraguay de la aplicación de la salvaguardia, sino por falta de motivación, pues dicha resolución no había analizado si tal exclusión constituía o no una violación al principio de nación más favorecida.

36 Recogidas en la Interpretación Prejudicial 103-IP-2000 del 2 de mayo de 2001, publicada en la Gaceta Oficial del Acuerdo de Cartagena 677 del 13 de junio de 2001.

37 Como es el caso de las medidas correctivas previstas en los artículos 90 y 96 del Acuerdo de Cartagena.
Adicionalmente, el voto en minoría explicó que la salvaguardia solo se hubiese justificado si las importaciones provenientes de los demás países miembros de la Comunidad Andina eran la única causa, o una de las principales causas, del desequilibrio en la balanza de pagos ecuatoriana. De lo contrario, la salvaguardia no tendría la naturaleza de medida correctiva. Si las importaciones provenientes de Colombia y Perú no eran la causa, o una de las causas, del desequilibrio en la balanza de pagos, la salvaguardia aplicada a dichas importaciones carecía de sentido, pues no habría corregido la causa real del desequilibrio. Se trataría de una salvaguardia injustificada y desproporcionada que afectaba a las importaciones andinas.

La posición en minoría constató, de la información económica que obraba en el expediente, que las importaciones provenientes de Perú y Colombia habían sido proporcionalmente menores a las importaciones provenientes de otros países. No solo eso, también evidenció que en la relación comercial que Ecuador tenía con Perú y Colombia, las exportaciones hacia Ecuador habían disminuido en mayor grado que las exportaciones desde Ecuador. Así, por ejemplo, en el año 2014, las importaciones provenientes de Colombia y Bolivia habían disminuido en 4,6 \% y las provenientes de Perú habían decrecido en $8,3 \%$, mientras que las provenientes de otros países habían aumentado en 16,2 \%. Para el voto en minoría, las importaciones provenientes de Colombia y Perú no estaban relacionadas con el desequilibrio en la balanza de pagos global de Ecuador, fenómeno más bien relacionado con la disminución del precio de las exportaciones petróleo ecuatoriano. Para ver el voto en minoría, observar el Gráfico 1. 


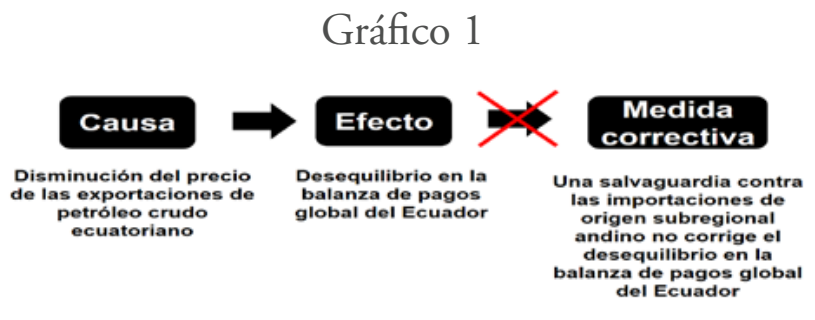

Para los magistrados que votaron en minoría, el análisis efectuado por la SGCA fue errado. $\mathrm{Al}$ no haber evaluado este órgano comunitario si las importaciones provenientes de los demás países andinos eran la causa, o una de las causas, del déficit comercial, no se percató que la balanza de pagos entre Ecuador y Perú había sido superavitaria para el primero, lo que significaba que en realidad su relación comercial con Perú había sido beneficiosa en términos de mitigar el desequilibrio en la balanza de pagos global originada por la caída del precio del petróleo.

Como se puede advertir, el voto en mayoría no analizó como requisito de la medida adoptada por el Ecuador la "relación causal", es decir, que el incremento de las importaciones provenientes de uno o más países miembros debía ser la causa, o al menos una de las causas, del desequilibrio en su balanza de pagos global. En cambio, el voto en minoría consideró que dicho requisito sí era exigible, además de que la salvaguardia debía tener carácter correctivo, temporal y excepcional, por lo que estaba sujeta a una interpretación restrictiva.

\section{Proceso 01-AN-2015: salvaguardia por deva- luación monetaria (sentencia del 23 de agos- to de 2018)}

Según Ecuador, desde el 2013 se habría iniciado un proceso de depreciación paulatina del peso colombiano y el sol peruano, con una profundización en los últimos meses del 2014, lo cual habría provocado una pérdida de com- petitividad de las exportaciones ecuatorianas. Por esta razón, el 24 de diciembre de 2014, Ecuador solicitó a la SGCA autorización para aplicar una salvaguardia por devaluación monetaria con carácter de emergencia.

Días después, y mediante Resolución 050 del COMEX del 29 de diciembre de $2014^{38}$, Ecuador resolvió aprobar la aplicación de una medida correctiva en los términos del artículo 98 del Acuerdo de Cartagena (salvaguardia cambiaria) para los productos originarios de Perú y Colombia, consistente en un derecho aduanero ad valorem del $7 \%$ sobre productos peruanos y del 21\% sobre productos colombianos, a partir del 5 de enero de 2015. Como es evidente, Perú y Colombia se opusieron a la referida salvaguardia.

Luego del análisis correspondiente, mediante Resolución 1762 del 6 de febrero de $2015^{39}$, la SGCA concluyó que para el periodo comprendido entre julio y diciembre de 2014 se había verificado una depreciación en términos generales de $26,1 \%$ del peso colombiano y $6,1 \%$ de sol peruano, pero como resultado de causas exógenas a la sola intervención de los bancos centrales colombiano y peruano. Respecto de la alteración de las condiciones normales de competencia, verificó que en el periodo comprendido entre agosto y diciembre de 2014 no había existido relación causal entre el deterioro de la balanza comercial del Ecuador y la depreciación de las monedas colombiana y peruana. En opinión de la SGCA, el déficit en dicha balanza era consecuencia de las condiciones de la relación comercial existente entre Ecuador y China.

38 Publicada en el Segundo Suplemento del Registro Oficial del Ecuador 408 del 5 de enero de 2015.

39 Publicada en la Gaceta Oficial del Acuerdo de Cartagena 2448 el mismo día. 
En efecto, tratándose del perjuicio aludido y su eventual relación con la depreciación del peso colombiano y el sol peruano, la SGCA no encontró una relación causal entre el deterioro de las exportaciones ecuatorianas y la depreciación de las monedas colombiana y peruana, siendo que el déficit en la balanza comercial se explicaba, principalmente, por el comercio con China. En ese sentido, la SGCA denegó la autorización para la aplicación de la salvaguardia prevista en el artículo 98 del Acuerdo de Cartagena, propuesta por el gobierno ecuatoriano en contra de las importaciones originarias de Colombia y Perú $y$, en consecuencia, resolvió que el gobierno ecuatoriano debía disponer su levantamiento de manera inmediata.

El pronunciamiento de la SGCA no fue satisfactorio para Ecuador, por lo que el 6 de marzo de 2015 presentó una demanda ante el TJCA solicitando la nulidad de la Resolución 1762, y argumentando, principalmente40, que para la aplicación de la salvaguardia cambiaria prevista en el artículo 98 del Acuerdo de Cartagena se requerían como únicas condiciones habilitantes: (i) la verificación de la devaluación monetaria hecha por un país miembro diferente al solicitante, y (ii) la alteración en las condiciones normales de competencia en dicho país; por lo que, en su opinión, la resolución de la SGCA había desnaturalizado el carácter preventivo de la medida de emergencia, sugiriendo que sea únicamente de carácter correctivo al señalar que para emitir su dictamen, ella debía verificar previamente la existencia de perjuicios inmediatos y medibles en el mercado del país miembro solicitante. Adicionalmente, argumentó que la SGCA había realizado una in-

40 En su escrito de demanda y alegatos finales. necesaria distinción entre depreciación y devaluación, cuando el artículo 98 del Acuerdo de Cartagena habla de devaluación y los precedentes de la propia SGCA señalaban que los términos devaluar o depreciar significaban lo mismo.

La SGCA contestó la demanda solicitando que sea declarada infundada ${ }^{41}$. En su escrito de contestación y alegatos finales, la SGCA argumentó, principalmente, que el artículo 98 dispone que la medida debe ser "efectuada" por un país miembro, lo que implica la presencia de algún elemento de intervención administrativa en el mercado con el fin de alterar las condiciones de competencia, comprobándose en el caso concreto que las intervenciones realizadas por los bancos centrales de los países vecinos no habían tenido fines competitivos, sino todo lo contrario, habían sido efectuadas con el objetivo de evitar una mayor caída del valor de sus monedas locales. En lo que respecta al nexo causal, señaló que había analizado la alteración en las condiciones de competencia, la cual sí había existido, pero que en lo sustantivo se había originado por causas ajenas a las depreciaciones de las monedas colombiana y peruana. Finalmente, sostuvo que, en cuanto al perjuicio -o la perturbación-, se comprobó que no se había producido un efecto negativo en los flujos comerciales ecuatorianos, presentándose además un superávit respecto del Perú.

El 23 de agosto de 2018, el Tribunal adoptó Sentencia ${ }^{42}$ con la disidencia parcial de uno de

41 En este punto, cabe mencionar que Perú se apersonó al proceso en calidad de coadyuvante de la SGCA.

42 Recaída en el Proceso 01-AN-2015, publicada en la Gaceta Oficial del Acuerdo de Cartagena 3369 del 13 de setiembre de 2018. 
los magistrados ${ }^{43}$. El TJCA declaró infundada en todos sus extremos la demanda presentada por Ecuador. Con este fallo, el TJCA regresó a la línea jurisprudencial detallada en la sección 4 del presente capítulo, tal como se aprecia en el siguiente criterio jurisprudencial —adoptado por unanimidad - contenido en dicha providencia judicial:

...se advierten como características comunes a todas las modalidades de salvaguardias (por desequilibrio en la balanza de pagos, por cumplimiento del Programa de Liberación, de productos específicos y por devaluación monetaria), las siguientes:

(i) Son medidas de naturaleza correctiva.

(ii) Son medidas de carácter transitorio.

(iii)Son medidas de carácter excepcional, por lo que están sujetas a una interpretación restrictiva, y solo pueden ser conferidas en estricto cumplimiento de todos y cada uno de sus requisitos.

(iv) Les es exigible el requisito de la "relación causal". Ello es así debido a la naturaleza correctiva de todas estas medidas. Al ser las salvaguardias medidas correctivas, lo que buscan corregir se encuentra vinculado con aquello que causa el daño o la amenaza de daño. $\mathrm{Si}$ las importaciones provenientes de otro país miembro no son la causa, o no coadyuvan a la causa, del desequilibrio en la balanza de pagos global ${ }^{10}$, de los perjuicios graves a la economía del país ${ }^{11}$, de la perturbación en la pro-

43 El disentimiento parcial se dio respecto de los párrafos 3.2.28 al 3.4.26 de la Sentencia. ducción nacional ${ }^{12}$ o de la alteración de las condiciones normales de competen$\mathrm{cia}^{13}$, carece de sentido afectar dichas importaciones a través de la aplicación de alguna de las cuatro modalidades de salvaguardias antes mencionadas.

Las importaciones o el incremento de determinadas importaciones tienen que ser el hecho causal, o contribuir como hecho causal, del dańo o amenaza de daño, siendo que este daño puede ser el desequilibrio en la balanza de pagos global, los perjuicios graves a la economía del país, la perturbación en la producción nacional o la alteración de las condiciones normales de competencia, según la salvaguardia de que se trate.

(v) Deben ser proporcionales al hecho que las genera. Esto significa que se procurará que no afecten el comercio de los productos incorporados al Programa de Liberación ${ }^{14}$, no podrán implicar una disminución de las importaciones del producto o productos de que se trate (con respecto a los doce meses anteriores) ${ }^{15}$, se deberá garantizar el acceso de un volumen de comercio no inferior al promedio de los tres últimos años ${ }^{16}$, o no podrán significar una disminución de los niveles de importación existentes antes de la devaluación ${ }^{17}$, según la salvaguardia de que se trate.»

«10 Este es el efecto que habilitaría la aplicación de la medida correctiva denominada salvaguardia por desequilibrio en la balanza de pagos global prevista en el artículo 95 del Acuerdo de Cartagena.

11 Este es el efecto que habilitaría la aplicación de la medida correctiva denomi- 
nada salvaguardia por el cumplimiento de programa de liberación prevista en el artículo 96 del Acuerdo de Cartagena.

12 Este es el efecto que habilitaría la aplicación de la medida correctiva denominada salvaguardia de productos específicos prevista en el artículo 97 del Acuerdo de Cartagena.

13 Este es el efecto que habilitaría la aplicación de la medida correctiva denominada salvaguardia por devaluación monetaria prevista en el artículo 98 del Acuerdo de Cartagena

14 Para el caso de la salvaguardia por desequilibrio en la balanza de pagos global prevista en el artículo 95 del Acuerdo de Cartagena.

15 Para el caso de la salvaguardia por el cumplimiento de programa de liberación prevista en el artículo 96 del Acuerdo de Cartagena.

16 Para el caso de la salvaguardia de productos específicos prevista en el artículo 97 del Acuerdo de Cartagena.

17 Para el caso de la salvaguardia por devaluación monetaria prevista en el artículo 98 del Acuerdo de Cartagena.

El criterio jurídico citado guarda correspondencia conceptual con la jurisprudencia emitida por el TJCA (sentencias e interpretaciones prejudiciales) desde 1987 hasta antes del 2018, relacionada con las salvaguardias reguladas en el capítulo XI del Acuerdo de Cartagena, tal como se explicó en la sección 4 del presente trabajo.

Luego de exponer los criterios generales de todas las salvaguardias reguladas en el Acuerdo de Cartagena, la sentencia, por unanimidad, se centró en el objeto, contenido y alcance de la salvaguardia por devaluación monetaria, precisando que del artículo 98 del Acuerdo de Cartagena y de la jurisprudencia previa desarrollada por el TJCA ${ }^{44}$ se advertían los siguientes requisitos sustantivos aplicables a este tipo de salvaguardia:

(i) Que se haya producido una devaluación monetaria efectuada por un país miembro (causa).

(ii) Que dicha devaluación altere las condiciones normales de competencia de otro país miembro (efecto). Esta alteración implica un cambio significativo en las importaciones y exportaciones del país miembro afec$\operatorname{tado}^{45}$.

(iii)La existencia de relación causal; es decir, la devaluación monetaria efectuada por un país miembro tiene que ser la causa de la alteración de las condiciones normales de competencia (efecto) en el país miembro que solicita la salvaguardia por devaluación monetaria (medida correctiva). Por ello, la SGCA deberá verificar la perturbación que produce en el país afectado (país solicitante de la medida correctiva) la devaluación ocurrida en otro de los países miembros.

44 Sentencias recaídas en los Procesos 1-N-86 del 10 de junio de 1987, 2-N-86 del 10 de junio de 1987 y 4-AN97 del 17 de agosto de 1998, así como la Interpretación Prejudicial 103-IP-2000 del 2 de mayo de 2001 (todas ellas mencionadas en la sección 4 del presente capítulo).

45 Respecto de este requisito, la Sentencia precisa que, a raíz de la devaluación monetaria, en el país miembro afectado se incrementan de modo significativo las importaciones provenientes del país miembro que implementó la devaluación monetaria y, a su vez, se reducen significativamente las exportaciones del país miembro afectado que se dirigen al país miembro que implementó la devaluación monetaria. 
Para el análisis de este requisito, previamente, se tiene que demostrar el cumplimiento de los requisitos sustantivos (i) y (ii). Por tanto, bastaría que no se demuestre el cumplimiento de los requisitos sustantivos (i) o (ii) para que carezca de sentido analizar la existencia de la relación causal.

(iv) Que la medida sea correctiva y transitoria (mientras subsista la alteración), dentro de las recomendaciones de la SGCA, y que su aplicación no signifique una disminución de los niveles de importación existentes antes de la devaluación.

Para explicar con mayor claridad los referidos requisitos sustantivos, la sentencia utilizó el Gráfico 2.

La sentencia, por unanimidad, precisó que la causa de la alteración de las condiciones normales de competencia en el país miembro solicitante de la salvaguardia debe ser la devaluación monetaria efectuada por otro país miembro y que, en consecuencia, la medida correctiva resulta ser la aplicación de una salvaguardia por devaluación monetaria de conformidad con lo establecido en el artículo 98 del Acuerdo de Cartagena. Agregó que, no se cumpliría el requisito de la relación causal si la causa, o principal causa de la alteración de las condiciones normales de competencia, fuese distinta a la devaluación monetaria efectuada por un país miembro, tal como lo explican los Gráficos 3 y 4, contenidos en la sentencia.

Adicionalmente, la sentencia, por unanimidad, señaló que se debían tener en cuenta las siguientes consideraciones adicionales: (i) cualquiera de los países miembros puede pedir a la Comisión una decisión definitiva del asunto; (ii) el país miembro que devaluó puede pedir a
Gráfico 2

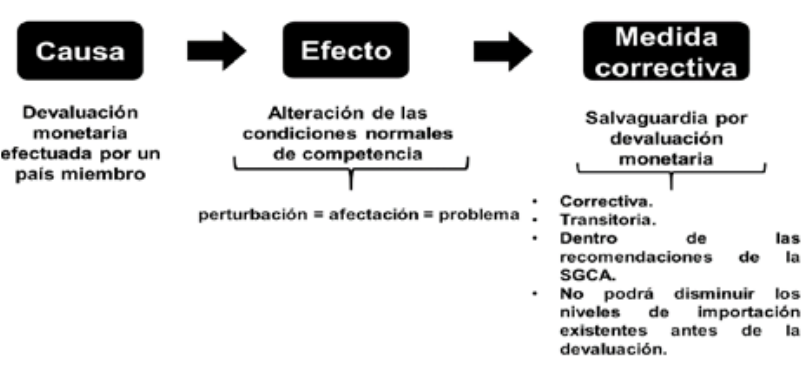

Gráfico 3

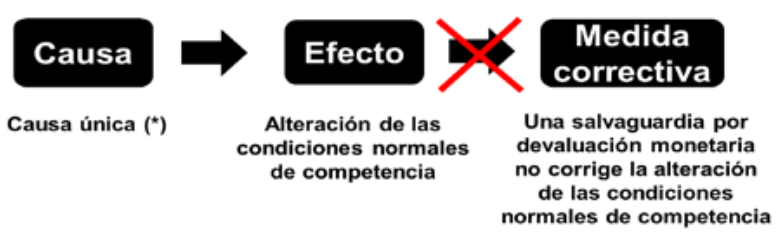

(*) Situación distinta a la devaluación monetaria efectuada por un pais miembro.

\section{Gráfico 4}

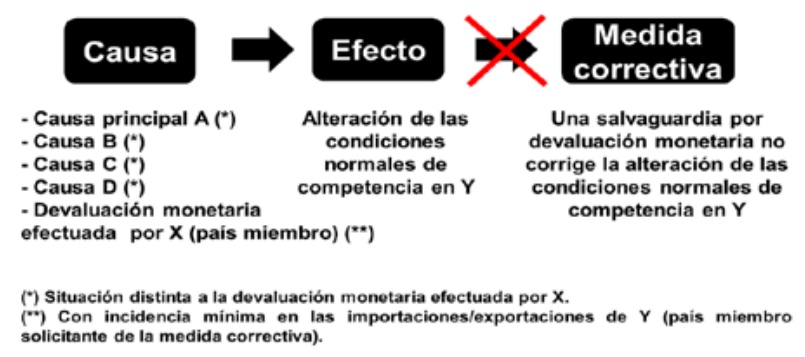

la SGCA, en cualquier momento, que revise la situación, a fin de atenuar o suprimir las mencionadas medidas correctivas.

El dictamen de la SGCA puede ser enmendado por la Comisión; y, (iii) al ser una medida de carácter excepcional, está sujeta a una interpretación restrictiva, por lo que solo puede ser conferida en estricto cumplimiento de todos y cada uno de sus requisitos.

Luego de explicar los criterios comunes a todas las modalidades de salvaguardias y centrarse en las características de la salvaguardia por devaluación monetaria, la sentencia procedió a ana- 
lizar si la solicitud — con carácter de emergencia- para la adopción de la medida correctiva regulada en el artículo 98 del Acuerdo de Cartagena (salvaguardia por devaluación monetaria), presentada por Ecuador, había cumplido o no con los requisitos antes referidos.

Antes de evaluar el primer requisito — que un país miembro haya efectuado una devaluación monetaria, la cual debe ser la causa de la alteración ${ }^{46}$ de las condiciones normales de competencia en el país miembro afectado-, la posición mayoritaria del TJCA consideró necesario conceptualizar el término "devaluación monetaria" y diferenciarlo del término "depreciación monetaria”. En ese sentido, precisó que la devaluación monetaria a que se refiere el artículo 98 del Acuerdo de Cartagena consiste en la alteración del tipo de cambio efectuada por el poder ejecutivo de un país miembro (o su banco central ${ }^{47}$ ) con el objeto de que la moneda local (por ejemplo, el peso colombiano o el sol peruano) pierda valor frente a la moneda extranjera (por ejemplo, el dólar de los Estados Unidos de América). Mientras que, la depreciación monetaria ocurre cuando dicha pérdida de valor se origina por la interacción entre la oferta y demanda de ambas divisas sin intervención del poder ejecutivo del país miembro (o de su banco central). Añadió que, la devaluación monetaria puede ocurrir tanto en el sistema de cambio fijo como en el sistema de cambio flotante. En este segundo caso,

46 La Sentencia precisó que esta alteración consiste en que se incrementan sustancialmente las importaciones provenientes del país miembro que implementó la devaluación $y$, a su vez, disminuyen significativamente las exportaciones que se dirigen al país miembro que devaluó su moneda.

47 Los Bancos Centrales de los países miembros de la Comunidad Andina son: (i) Banco Central de Bolivia; (ii) Banco Central del Ecuador; (iii) Banco de la República de Colombia; y, (iv) Banco Central de Reserva del Perú. la devaluación se suele ejecutar mediante la compra de la moneda extranjera (por ejemplo, dólares americanos) por parte del respectivo banco central. Dado que esta clase de banco suele comprar y vender dólares americanos con el fin de controlar la volatilidad del tipo de cambio (para evitar cambios bruscos del tipo de cambio), debe diferenciarse la compra ordinaria que tiene por objeto el control de la volatilidad del tipo de cambio de una auténtica devaluación monetaria.

Dicho esto, la posición mayoritaria concluyó que habrá devaluación monetaria —en los términos del artículo 98 del Acuerdo de Cartagena- en un sistema de cambio flotante cuando la compra significativa de una moneda extranjera (por ejemplo, dólares americanos) por parte del banco central origine que la moneda local pierda valor frente a la moneda extranjera en un periodo de tiempo suficiente para incrementar las exportaciones y reducir las importaciones ${ }^{48}$, por lo que la devaluación monetaria

48 Para entender claramente la vinculación entre, de un lado, la devaluación monetaria y, del otro, el incremento de las exportaciones y la reducción de las importaciones, la Sentencia planteó el siguiente ejemplo con el sol peruano y el dólar americano. Asumamos (de manera hipotética) que en el Perú el tipo de cambio es US\$ $1=$ S/ 2. Luego, el Banco Central de Reserva del Perú procede a comprar dólares (de manera significativa), logrando que el tipo de cambio llegue a US\$ $1=$ S/ 4 .

Si antes de la devaluación el precio final del producto "X" a ser exportado era de S/ 10 (equivalente a US\$ 5), luego de la devaluación su precio final seguirá siendo $S / 10$, pero en dólares americanos pasará a ser de US\$ 2,5. Su precio de exportación ha disminuido con la devaluación (con la devaluación monetaria las exportaciones tienden a incrementarse, pero no debido a una mayor eficiencia económica, sino como consecuencia de dicha devaluación).

Asimismo, si antes de la devaluación un producto importado costaba US\$10, al consumidor peruano le costaba S/ 20. Luego de la devaluación, al consumidor peruano el mismo producto le cuesta S/ 40 (la devaluación produce un impacto en las importaciones, las que tienden a 
suele tener un efecto doble: abarata el precio de exportación de los productos fabricados en el país que devalúa su moneda y encarece en dicho país el precio de importación de los productos que vienen del extranjero.

Luego de esta precisión, la posición mayoritaria procedió a analizar si Ecuador, al momento de solicitar autorización para la aplicación de la medida correctiva regulada en el artículo 98 del Acuerdo de Cartagena, había cumplido o no con el requisito sustantivo consistente en que se haya producido una devaluación monetaria efectuada por un país miembro. Para ello, primero evaluó la relación Perú-Ecuador, y luego la relación Colombia-Ecuador.

Respecto de la presunta devaluación monetaria efectuada por Perú, la posición mayoritaria advirtió que Perú había reducido significativamente la compra de dólares en el ańo 2013, comparado con lo que había adquirido el año 2012. Y en el ańo 2014, periodo dentro del cual se habría producido la presunta "devaluación monetaria” ${ }^{49}$, la información proporcionada demostró que el Banco Central de Reserva del Perú, en lugar de comprar dólares, había procedido a venderlos, todo lo contrario a una devaluación monetaria, por lo que las cifras evidenciaban que la subida del tipo de cambio se había debido a factores distintos a una presunta devaluación monetaria. Esto es, en el caso peruano, resultó manifiestamente evidente que no había habido devaluación monetaria alguna en el año 2014, pues el banco central peruano no había comprado dólares ese año, sino que los había vendido.

disminuir debido a que los productos importados en dólares americanos se han vuelto más caros).

49 De julio a diciembre de 2014, según lo alegado por Ecuador en su solicitud para la adopción de la medida correctiva regulada en el artículo 98 del Acuerdo de Cartagena (salvaguardia por devaluación monetaria).
Tratándose de la presunta devaluación monetaria efectuada por Colombia, la posición mayoritaria mencionó que en el año 2014, periodo dentro del cual se habría producido la presunta "devaluación monetaria" ${ }^{50}$, Colombia había comprado menos dólares que en los promedios mensuales de los años 2011 y 2012, y en los últimos meses del año 2014 había comprado inclusive en menor cantidad que en tales promedios. Asimismo, mencionó que en el año 2014, Colombia, en lugar de comprar más dólares — de manera significativa-, había adquirido en menor cantidad la divisa estadounidense, razón por la cual no era posible asumir que había habido devaluación monetaria en los términos del artículo 98 del Acuerdo de Cartagena.

Con esta última Sentencia, y consciente de los beneficios del programa de liberación, el TJCA ha establecido criterios que fortalecen el libre comercio; esto es, requisitos exigentes y concurrentes para que un país miembro imponga una medida de salvaguardia que afecte las importaciones provenientes de otro u otros países miembros. La razón para entender el carácter excepcional de dichas medidas y realizar una interpretación restrictiva de su aplicación es, sin lugar a dudas, la necesidad de fortalecer el libre comercio en la Comunidad Andina ${ }^{51}$.

50 De julio a diciembre de 2014, según lo alegado por Ecuador en su solicitud para la adopción de la medida correctiva regulada en el artículo 98 del Acuerdo de Cartagena (salvaguardia por devaluación monetaria).

51 Gómez, H. Fortaleciendo el libre comercio en la Comunidad Andina. Negocios Internacionales, Revista de la Sociedad de Comercio Exterior del Perú - COMEXPERU, vol. 23, núm. 254, p. 18. Lima, febrero 2019. Disponible en: https://www.comexperu.org.pe/upload/articles/ revista/febrero2019/mobile/index.html $\mathrm{p}=18$ (Consultado realizada el 10 de octubre de 2020) 


\section{CONCLUSIONES}

Las salvaguardias son medidas de defensa comercial que tienen por finalidad proteger a una rama de la industria nacional que sufre un daño, o amenaza de daño, como consecuencia del incremento imprevisto de importaciones de productos competidores a los fabricados por dicha industria. Dichas medidas, que traducen una política comercial, consisten en restricciones a las importaciones y pueden expresarse en un aumento de los aranceles o en el establecimiento de cuotas de importación.

Las medidas de salvaguardia son válvulas de escape a los compromisos arancelarios asumidos en el marco de la Organización Mundial del Comercio (OMC), los acuerdos de libre comercio, o los procesos de integración económica y social como la Comunidad Andina. Es así que el Acuerdo de Cartagena prevé en su capítulo XI cuatro modalidades de salvaguardia comercial: por desequilibrio en la balanza de pagos global (artículo 95), por el cumplimiento del programa de liberación (artículo 96), por productos específicos (artículo 97) y por devaluación monetaria (artículo 98). La Decisión 389 de la Comisión de la Comunidad Andina regula el procedimiento y las medidas correctivas de la salvaguardia por desequilibrio en la balanza de pagos global.

Entre 1987 y hasta antes del 2018, el Tribunal de Justicia de la Comunidad Andina (TJCA) desarrolló criterios jurídicos respecto de las cuatro modalidades de salvaguardia comercial. Conforme a dichos criterios, si bien tales medidas tenían particularidades propias, todas ellas compartían, como requisitos comunes, el tener naturaleza correctiva, carácter temporal y excepcional, y la relación de causalidad. Dada su naturaleza excepcional, debían ser aplicadas e interpretadas de modo restrictivo. La causa- lidad significaba que debía existir una relación de causa y efecto entre el incremento de las importaciones y el daño (o amenaza de daños) de que se trataba.

En el 2018, el TJCA expidió dos sentencias en materia de salvaguardia comercial. La primera sentencia, adoptada por mayoría en abril de ese año, trataba sobre la salvaguardia por desequilibrio en la balanza de pagos global adoptada por Ecuador en marzo de 2015. El voto en mayoría de esta sentencia no analizó como requisito de dicha salvaguardia la "relación causal", es decir, que el incremento de las importaciones provenientes de uno o más países miembros debía ser la causa, o al menos una de las causas, del desequilibrio en la balanza de pagos global. El voto en minoría, en cambio, consideró que dicho requisito sí era exigible, además de que la salvaguardia debía tener carácter correctivo, temporal y excepcional, por lo que estaba sujeta a una interpretación restrictiva.

La segunda sentencia, adoptada en agosto de 2018, se pronunció sobre la salvaguardia por devaluación monetaria adoptada por Ecuador en enero de 2015. En esta sentencia, el TJCA estableció que las cuatro modalidades de salvaguardia previstas en el capítulo XI del Acuerdo de Cartagena tienen las siguientes características comunes:

- Son medidas de naturaleza correctiva y carácter transitorio y excepcional, por lo que están sujetas a una interpretación restrictiva, y solo pueden ser adoptadas en estricto cumplimiento de todos y cada uno de sus requisitos.

- Les es exigible el requisito de la "relación causal” (causa y efecto). Ello es así debido a la naturaleza correctiva de todas estas medidas. Al ser las salvaguardias medidas 
correctivas, lo que buscan corregir se encuentra vinculado con aquello que causa el daño o la amenaza de daño. Si las importaciones provenientes de otro país miembro no son la causa, o no coadyuvan a la causa, del desequilibrio en la balanza de pagos global, de los perjuicios graves a la economía del país, de la perturbación en la producción nacional o de la alteración de las condiciones normales de competencia, según corresponda, carece de sentido afectar dichas importaciones a través de la aplicación de alguna de las cuatro modalidades de salvaguardias antes mencionadas.

Las importaciones o el incremento de determinadas importaciones tienen que ser el hecho causal, o contribuir como hecho causal, del daño o amenaza de dańo, siendo que este daño puede ser el desequilibrio en la balanza de pagos global, los perjuicios graves a la economía del país, la perturbación en la producción nacional o la alteración de las condiciones normales de competencia, según la salvaguardia de que se trate.

- Deben ser proporcionales al hecho que las genera. Esto significa que se procurará que no afecten el comercio de los productos incorporados al programa de liberación, no podrán implicar una disminución de las importaciones del producto o productos de que se trate (con respecto a los doce meses anteriores), se deberá garantizar el acceso de un volumen de comercio no inferior al promedio de los tres últimos años, o no podrán significar una disminución de los niveles de importación existentes antes de la devaluación, según la salvaguardia de que se trate.
El programa de liberación contemplado en el capítulo VI del Acuerdo de Cartagena permite la existencia de un área de libre comercio en la Comunidad Andina, lo que beneficia a los más de 111 millones de consumidores andinos con la posibilidad de acceder a una mayor oferta de productos provenientes del comercio intracomunitario, lo que incrementa la competencia. El resultado de esta mayor competencia es que dichos consumidores obtienen productos a menores precios, de mejor calidad y en mayor variedad.

Las medidas de salvaguardia afectan al programa de liberación y al libre comercio, por lo que deben ser interpretadas de modo restrictivo. Con la sentencia de agosto de 2018, el TJCA ha establecido criterios que fortalecen el libre comercio, pues ha señalado requisitos exigentes y concurrentes para que un país miembro imponga una medida de salvaguardia que afecte las importaciones provenientes de otro u otros países miembros. La razón para entender el carácter excepcional de dichas medidas y realizar una interpretación restrictiva de su aplicación es, sin lugar a dudas, la necesidad de fortalecer el libre comercio en la Comunidad Andina, una de las mayores virtudes del proceso de integración subregional andino.

\section{BIBLIOGRAFÍA}

Delpiano, C. Medidas de salvaguardia y exclusiones regionales en la jurisprudencia de la Organización Mundial del Comercio. Revista Chilena de Derecho, vol. 42, núm. 2. Pontificia Universidad Católica de Chile, Santiago, 2015. Disponible en: https://scielo.conicyt.cl/scielo.php?script=sci_arttext\&pid=S0718-34372015000200007 (consultado el 19 de octubre de 2020)

Ibarra, G. Las grandes controversias del multilateralismo. Crisis del principio de la Nación más favorecida, distorsiones de la competencia y temas ambienta- 
les, Facultad de Ciencias Jurídicas de la Pontificia Universidad Javeriana - Legis Editores S.A., Bogotá, 2018.

Gómez, H. El ordenamiento jurídico comunitario andino. En: Gómez H. (Director). Apuntes de Derecho Comunitario Andino. A propósito de los 50 años de la Comunidad Andina y los 40 años de creación de su Tribunal de Justicia. Portoviejo: Universidad San Gregorio de Portoviejo, Editorial San Gregorio S. A., 2019.
Gómez, H. Fortaleciendo el libre comercio en la Comunidad Andina. Negocios Internacionales. Revista de la Sociedad de Comercio Exterior del Perú-COMEXPERU, vol. 23, núm. 254, Lima, febrero 2019. Disponible en: https://www.comexperu.org.pe/upload/articles/revista/ febrero2019/mobile/index.html\#p=18 